\title{
Causal Explanations of Defection: A Knowledge Structure Approach
}

\author{
Constantine Sedikides \\ University ofWisconsin-Madison \\ Craig A. Anderson \\ University ofMissouri-Columbia
}

In still other cases, we engage in concentrated cau analyses of another person's behavior as we try to in pret it and make judgments about it. In deciding hov deal with a world leader during a crisis, a policymal must make causal attributions about past behaviors : use causal models to make predictions about the fut In deciding whom to hire for the new junior sor position, senior faculty members engage in a similar $t$ of causal analysis.

The consequences of mistakes in these various ju ments under uncertainty range from the trivial to $t$ devastating. A mistake in judging the intentions of world leader can have catastrophic results to natic (e.g., war), whereas a mistake in judging the social $\mathrm{j}$ candidates has a rather modest impact to a limited nv ber of people. Nonetheless, research from a variety areas converges on the similarity of judgment process across domains (e.g., Anderson, New, \& Spear, 19: Anderson \& Weiner, in press; Black, Galambos, \& Re 1984; Kahneman, Slovic, \& Tversky, 1982; Kruglans 1989; Nisbett \& Ross, 1980). Specifically, it appears t causal inferences about another person are frequer based on causal knowledge structures. That is, we $u$ packets of information (beliefs, social theories) abi how the world works in order to understand a partice act, to make inferences about the person and the situ: occupies many of our waking hours as we go about our daily tasks. In some cases, inferences are produced spontaneously. For example, merely reading that "the secretary solves the mystery halfway through the book" spontaneously produces the inference that the secretary is clever (Uleman, 1987, p. 337). In other cases, such spontaneous dispositional inferences are "corrected" for existing situational pressures, if sufficient cognitive resources are available. For instance, knowing that an anxiously behaving stranger was discussing her sexual fantasies mitigates the attribution that she is dispositionally anxious, but only if the attributor is not simultaneously enaged in additional absorbing cognitive tasks (Gilbert, Pelham, \& Krull, 1988).
Authors' Note: We thank Denis Hilton, Tom Ostrom, John Skowron and two reviewers for their insightful comments on earlier drafts. We thank James Beale and Tom Linneversfor their assistance with , collection and coding. Correspondence concerning this article should addressed to Constantine Sedikides, Psychology Department, Univer of Wisconsin-Madison, 1202 West Johnson Street, Madison, WI 537।

PSPB, Vol. 18 No. 4, August 1992 420-429

(C) 1992 by the Society for Personality and Social Psychology, Inc. 
tion, to predict future acts by the person or by other persons in that situation, and to select our own responses to the person.

Consider the case of an individual who has defected from his or her country to an ideological enemy country. What inferences do we draw about that individual? Why did he or she defect? Was the defection evidence of dispositional attributes? Was there something in the situation that caused the defection? What kind of person would take such drastic action? Answers to these quesdons determine our impressions of the person and ultimately determine how we act toward him or her. But answers to these questions will be based on our world knowledge about what motivates people in general, about the situation the person left, about the situation the person approached, and so on. This world knowledge (or stored causal inferences) constitutes a causal knowledge structure (CKS; Abelson, 1968, 1973; Hamilton, 1988; Hilton, 1988) . A key distinguishing feature of CKSs is that they link the various elements causally. That is, they contain causal beliefs about the target domain.

Of course, several CKSs may apply to a given behavioral act. Which CKS is used will depend on the specific characteristics of the situation, as well as on the momentary and/or chronic accessibility of CKSs to the person making the inferences. For instance, research on attributions for performance outcomes has demonstrated that different knowledge structures are used for interpersonal and noninterpersonal situations (e.g., Anderson, 1983, 1985). Similarly, motivational manipulations appear to exert their impact on attributions not through ego-defensive processes but through their effects on people's selection and application of knowledge structures (e.g., Anderson \& Slusher, 1986; see also Kunda, 1987, 1990). Research on the effects of differing goals on the interpretation and memory of events can also be interpreted within this CKS framework (e.g., Bower, 1976; Hoffman, Mischel, \& Mazze, 1981; Wyer, Srull, Gordon, \& Hartwick, 1982).

\section{TOWARD VALIDATING CAUSAL KNOWLEDGE STRUCTURES}

The construct of CKS has a respectable history in social and political psychology. Abelson (1968, 1973) and Kelley (1983) have referred to the construct as implicational molecules, political scripts, and perceived causal structures, respectively. (See also Axelrod, 1976; Conover \& Feldman, 1984; George, 1979; Hoagland \& Walker, 1979; Schank \& Abelson, 1977; Williams, 1984.) Although the concept of CKS has been used to explain many judgments and inference phenomena, tests of CKSs are relatively scarce, and the few existing ones have been criticized on numerous grounds. The most detailed critique of analyses of research on CKSs was provided by
Fiedler (1982). ${ }^{1}$ He has noted two major deficiencies in research attempting to validate the CKS construct: theo retical circularity and lack of naturalistic features.

In the first of his criticisms, Fiedler contended that CKS researchers infer the relevant CKS from subjects responses and subsequently employ that CKS to explair subjects' responses-clearly a circular use of the con struct. In his second criticism, Fiedler lamented the extensive prestructuring of stimulus information in CKs research, contending that experimenters overelaborate on the information they provide to subjects (see also Lalljee \&Abelson, 1983; Read, 1987). Fiedler noted that ex perimenters typically present their subjects with ready made inferences (e.g., referring to an actor's effort or ability) rather than raw informational material (e.g., an event). Such a presentation may force subjects to bypass the encoding and categorization stages of information processing, where CKSs are thought to have powerful effects.

To avoid the problem of circularity, Fiedler suggested three rules. The first rule, testability, refers to testing either structural or functional properties of CKSs (e.g., content distortions or intrusions) so that the construct can be rendered falsifiable. The second rule, variation, refers to establishing a rivalry between CKSs that are applicable to the same stimulus information (e.g., ma nipulating stimulus information so that it activates dif ferent CKSs). The third rule, converging operations refers to testing structural or functional CKS properties in multiple ways.

Fiedler also suggested three guidelines to reduce the problems associated with the prestructuring of stimulus information. The stimulus information should (a) be ambiguous regarding the proper way of encoding the in formation, (b) be complex enough to allow CKS-irrelevan interpretations, and (c) provide some causal cues to avoi random guessing biases.

The present research was designed to investigat CKSs using methods that meet the criteria set by Fiedler. In Experiment 1, CKSs were assessed by having (American) college students provide causal accounts of the reasons behind the defection of Soviets to the United States or Americans to the Soviet Union. This experiment was designed to obtain evidence for the existence of a defection CKS, based on subjects' verba] reports. Subsequent tests of the effects of CKSs would thus be independent of the demonstration of thei] existence.

In Experiment 2, the effects of CKSs were investigate by having subjects read an essay describing an inciden of defection. The essay referred to a family of eithe] Soviet or American defectors. For half the subjects, the dependent measures were collected immediately afte the presentation of the stimulus materials, whereas for the remaining half, the dependent measures were col- 


\section{PERSONALITYAND SOCIAL PSYCHOLOGY BULLETIN}

lected a week later. The effects of CKSs on memory and attributions were assessed. The testability problem was taken into consideration by testing functional properties of the CKSs through memory-oriented dependent mea-

sures (e.g., intrusions in subjects' free recall protocols). The inclusion of a delayed measure of recall was intended to maximize the sensitivity of the free recall test in detecting CKS-relevant intrusions. We assumed that intrusions are more likely to occur under delayed relative to immediate recall measures: Delayed recall forces subjects to rely on reconstructive memory, whereas less reconstruction is necessary in the case of immediate recall. The variation problem was considered by manipulating stimulus information (Soviet vs. American defectors) that supposedly would activate different CKSs.

The converging operations requirement was addressed by testing functional qualities of CKSs through both memorial and attributional measures (i.e., free recall, unsolicited attributions, open-ended attributions, and personality ratings). Again, the delayed measures were included in order to maximize the probability of detecting possibly weak effects. (For examples of use of delayed measures in the person perception and attribution literature, see Higgins, Rholes, \& Jones, 1977; Peterson, 1980; Wells, 1982.)

Experiment 2 fulfilled the prestructuring criterion in the following manner. First, the experimenter's intervention in the stimulus information (and, subsequently, the interference with subjects' encoding preferences) was minimized by providing subjects with event information rather than ready-made inferences about actors'

behaviors. Second, the event information was made sufficiently complex to allow alternative interpretations (e.g., subjects could attribute the defection to faults associated with the political/economic system, the personality of the defectors, or both). Finally, care was taken that the event information would provide for interpretational cues (e.g., by explicitly stating that the defectors opposed a war on foreign soil and fought for social freedoms).

\section{EXPERIMENT 1}

The purpose of this experiment was to validate the existence of a defection knowledge structure by eliciting subjects' open-ended causal accounts of defection. Defection is a rare but highly publicized event. We therefore expected most subjects to have given the issue some thought and to be familiar with culturally popular explanations of defection.

\section{Method}

Subjects. Sixty undergraduates participated as part of an introductory psychology course option. Subjects were run in groups of five to eight and were randomly as -
100

80

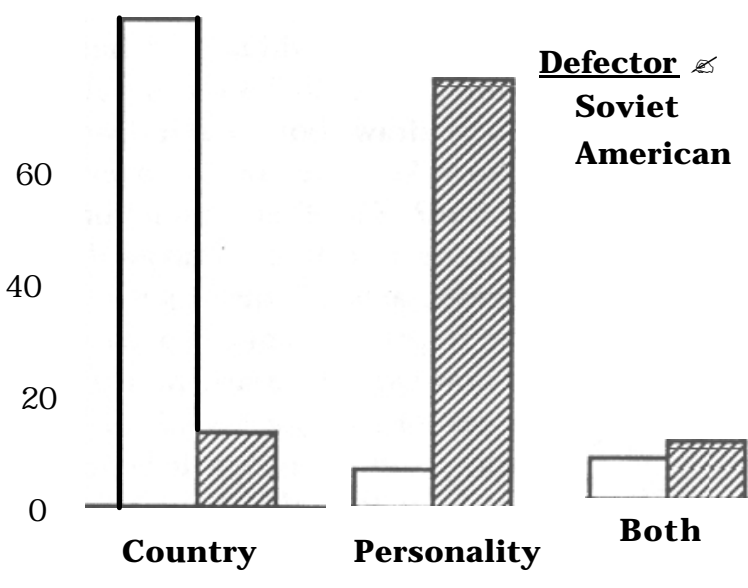

Type of Attribution

Figure 1 Percentage of subjects generating countryoriented, person oriented, or both types of attributions, Experiment 1.

signed to conditions. Dividers set on the tables in th experimental room prohibited subjects from seeing or another when seated.

Procedure. Half the subjects were given a sheet of pap bearing the following question on the top: "Sometim Soviet citizens defect to the United States. In genera why do you think Soviets defect to the United States' The remaining half encountered the question "Som times American citizens defect to the Soviet Union. general, why do you think Americans defect to the Sovi Union?" Subjects used the remainder of the page $\mathrm{fc}$ answering the question.

Coding. Two independent coders assigned t] reasons each subject provided for defection into one the following three categories: (a) Something about t] country is accountable for the defection, (b) somethir about the personality of the defector is accountable $f$ the defection, and (c) the country and the personali of the defector are equally accountable for $t$ ] defection. The coders agreed on $85 \%$ of the cases an resolved disagreements through discussion.

Results and Discussion

As shown in Figure 1, 87\% of the subjects who a swered the question on Soviet defectors to the Unite States stated that something about the country (e.g "an oppressive system," "the elimination of individu freedoms," "no opportunities to get rich") forc defection. In contrast, $77 \%$ of the subjects wl answered the question on American defectors to tr Soviet Union stated that something about t] defectors' personality (e.g., "confused," "traitors "ungrateful to their own coun- 
try") forces defection. Overall, the attributional patterns displayed for Soviet versus American defectors were significantly different, $\mathbf{x}^{2}(2)=33.97, \mathrm{p}<.0001$.

Thus, these results supply evidence for the psychological reality of a defection CKS. They demonstrated that American subjects (or, more precisely, those in our subject pool) provide differe nt causal accounts of defection depending on the nationality of the defector. Soviets defect because something is wrong with the system; Americans defect because something is wrong with them.

Experiment 1 established the existence of a defection CKS independently of its effects (see Fiedler, 1982). The goal of Experiment 2 was to further validate the defection CKS by examining its memorial and judgmental consequences.

\section{EXPERIMENT 2}

\section{Method}

$$
\text { SUBJECTS }
$$

Subjects were 120 undergraduates fulfilling an introductory psychology course option. The experiment was advertised on the sign-up board as an experiment that might require subjects to return to the laboratory after a week, same day and time. Subjects were run in groups of four to seven and were randomly assigned to conditions. Partitions set on the tables in the experimental room visually separated the subjects.

\section{DESIGN}

The design was a 2 (Defectors: Soviets, Americans) x 2 (Time Period: immediate recall, delayed recall) betweensubjects factorial.

\section{PROCEDURE}

On arriving at the experimental room, subjects were given the following instructions: "This is a reading comprehension study. You will soon be presented with a newspaper article, published several months ago in the New York Times. Please try to comprehend the article and familiarize yourself with it. At a later point in the study you will be asked to answer questions referring to the article." Next, subjects were presented with the "newspaper article." (The article, although not actually from the New York Times, was adapted from reports appearing in the press in summer 1986 and involving the defection of an American family to the Soviet Union.) Half the subjects read an article referring to Soviet defectors (Appendix A) and half read an article referring to American defectors (Appendix B). The content of the articles was the same except for the names of the defectors and the corresponding country or location names.

Subjects took approximately $2 \mathrm{~min}$ to read the article. After completing this task, half the subjects turned the page to find instructions telling them that the experiment was over and that they should return a week later These subjects completed the dependent measures at this later date. No additional information about the experiment was provided to the subjects. The other hal of the subjects were immediately paced through the dependent measures in the following order.

\section{DEPENDENT MEASURES}

Free recalL Subjects spent 5 min on a distractor task ir which they were given a list of the 50 states and were asked to fill in the capitals. They were then asked to recal all information contained in the article, being as specific as possible. Subjects wrote down all information on the same page.

Unsolicited attribution measure. Subjects completed an un-solicited attribution measure (Harvey, Yarkin, Lightner, \& Town, 1980) by writing down, in detail, all thoughts or feelings they might have had while reading the essay.

Open-ended attribution question. Subjects answered the following open-ended attribution question: "Why do you think the Andronovs [Perrins] defected to the United States [Soviet Union]?"

Personality ratings. Subjects rated the Andronovs (Perrins) on the personality trait dimensions intelligent, competent, warm, and moral. These trait dimensions were selected because they reflect the intellectual (i.e., intelligent, competent) and social (i.e., warm, moral) aspects of the evaluative personality dimension. Work by Rosenberg and his colleagues (Kim \& Rosenberg, 1980; Rosenberg, 1976; Rosenberg \& Sedlak, 1972; see also Osgood, Suci, \& Tannenbaum, 1957) has demonstrated that the evaluative dimension accounts for a great deal of the variance in people's social thinking.

Subjects were also asked to indicate how sympathetic o unsympathetic they felt toward the Andronovs (Perrins) All ratings were made on a scale ranging from 1 to 9 , with 1 anchoring the negative pole of the scale and 9 anchoring the positive pole.

Replication of Experiment 1. Finally, subjects answered the same question as in Experiment 1: "In general, why do you think Soviets [Americans] defect to the United States [Soviet Union]?"

Subjects were then debriefed, thanked for their participation, and excused.

\section{Results and Discussion}

Free recalL The free recall measure was employed to provide evidence for the existence of the defector CKS by testing its memorial properties. Research on knowledge structure functions (e.g., Bower, Black \& Turner, 1979; Bransford \& Franks, 1971; Markus, Crane, Bernstein, \& Siladi, 1982) has established that knowledge structures 


\section{PERSONALITYAND SOCIAL PSYCHOLOGY BULLETIN}

contribute to filling in missing data from a stimulus array. Knowledge structures lead to intrusions of stimuli not previously presented. Bower et al. (1979), for example, found that subjects who read that a story character went through the checkout line in a supermarket and then carried her groceries to the car were likely to "recall" that she had paid the checkout clerk, even though that event was not presented. If causal knowledge structures do exist, then we should be able to observe memory intrusions that have a causal flavor.

The present research examined the intrusion function of the defector CKS in two ways. First, the recall protocols of all 120 subjects were coded with regard to intrusions that were consistent with a "country-oriented" CKS - that is, with the notion that the defection of either the Soviet or the American family was due to deficiencies associated with the existing political or economic system in their respective countries. Examples of such intrusions were (a) the family defected because the husband was fired for political reasons, (b) the family opposed their country's foreign policy, and (c) the family was persecuted (e.g., private mail was opened, they were followed). Two coders, who were blind to the experimental design, to subjects' experimental conditions, and to the purposes of this research, broke down each recall protocol into independent thoughts and then decided which of these thoughts constituted intrusions (i.e., did not match the sentences contained in the original essay). The two coders agreed on $90 \%$ of the cases and resolved disagreements through discussion.

We performed both log-linear chi-square analyses and analyses of variance (ANOVAs) on the data. The chi-square analyses employed the number of subjects as the dependent measure. The ANOVAs used the number of intrusions as the dependent measure. (The number of intrusions ranged from 0 to 2.) We conducted both types of analyses because we thought that the memory consequences of CKSs would be best tested and understood through the use and convergence of multiple measures.

To provide evidence for the psychological existence of a country-oriented CKS, more subjects should make countryoriented intrusions for Soviet than for American defectors. The overall chi square was significant, $\mathrm{X}^{2}(3)=16.57, \mathrm{p}<.001$. As shown in the left half of Figure 2, $21.7 \%$ of subjects reading about Soviet defectors produced country-oriented intrusions as opposed to $8.3 \%$ of subjects reading about American defectors, $\mathrm{X}^{2}(1)=4.52$, $\mathrm{p}<.03$. Further, $21.7 \%$ of the subjects evidenced intrusions in the delayed recall condition, and only $8.3 \%$ did so in the immediate recall condition, $\mathrm{X}^{2}(1)=4.52, \mathrm{p}<$ .03. The interaction was significant, $\mathrm{X}^{2}(1)=4.05, p<.04$. Although country-oriented intrusions did not differ by nationality of defectors in the immediate recall con-

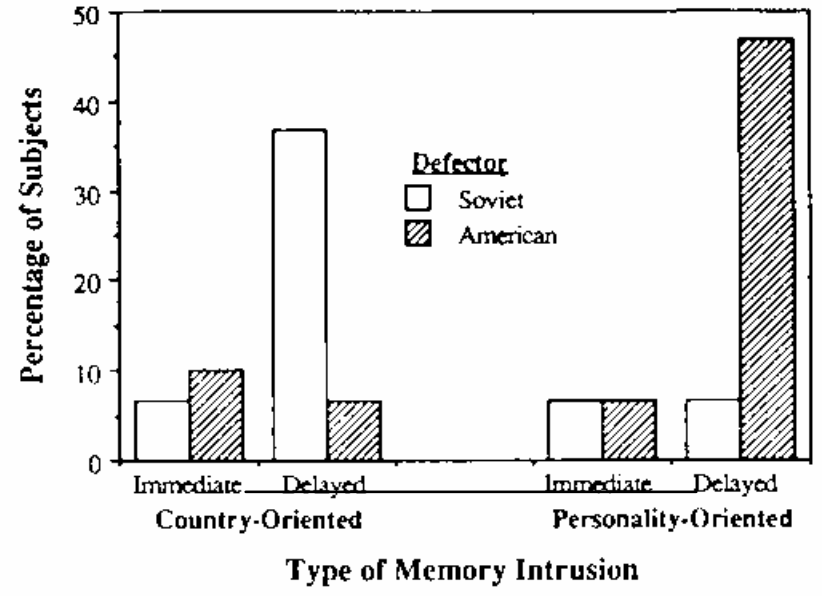

Figure 2. Percentage of subjects with countryoriented or personality oriented instrusions as a function of defectors and time period, Experiment 2.

dition, in the delayed recall condition most countryoriented intrusions occurred in conjunction with the Soviet defectors.

The ANOVAs produced results consistent with the chi-square analyses. Subjects made more intrusions when presented with the article about the Soviet $(M=$ $0.29)$ than the American defectors $(M=0.09), \mathrm{F}(1,116)$ $=6.92, \mathrm{p}<.009$. Further, subjects made more intrusions in the delayed $(M=0.29)$ than the immediate $(M=0.09)$ recall condition, $F(1,116)=6.92$, $\mathrm{p}<.009$. However, it was only under delayed recall that more intrusions associated with the Soviet $(M=0.50)$ than the American $(M=0.07)$ defectors were made, $F(1,116)=9.41, \mathrm{p}<.002$. (Means were 0.07 and 0.10 in the immediate recall condition for the Soviet and American defectors, respectively.)

To detect intrusions of a second sort, the recall protocols of all 120 subjects were again coded with respect to a "personality oriented" CKS - that is, the notion that the defection (of either the Soviet or the American family) was due to something about the defectors ' personality. Examples of such intrusions were (a) the husband was unhappy with his job, (b) the defectors were spies, and (c) the defectors reported on television that they disliked their country. The two coders agreed on $83 \%$ of the cases and resolved disagreements through discussion.

To provide evidence for the psychological existence of a personality-oriented CKS, more subjects should make personality-oriented intrusions for American than for Soviet defectors. The overall chi square was significant, $\mathrm{X}^{2}(3)=25.24, \mathrm{p}<.0001$. As can be seen in the right half of Figure 2, more subjects committed intrusions in con- 
junction with the American (26.65\%) than the Soviet $(6.7 \%)$ defectors, $x 2(1)=8.19$, $\mathrm{p}<.004$. Further, more subjects evidenced intrusions in the delayed recall $(26.65 \%)$ than the immediate recall condition $(6.7 \%), X^{2}(1)=9.17$, $\mathrm{p}<.002$. The interaction was significant, $\mathrm{X}^{2}(1)=3.61, \mathrm{p}$ $<$.05. Although personality-oriented intrusions did not differ in the immediate recall condition, in the delayed recall condition most personality-oriented intrusions concerned the American defectors.

The ANOVA results were congruent with the chi-square results. Subjects made more intrusions when presented with the article about the American defectors $(M=0.29)$ than the Soviet defectors $(M=0.09), \mathrm{F}(1,114)=$ $7.24, \mathrm{p}<.008$. Further, subjects made more intrusions in the delayed $(M=0.31)$ than the immediate $(M=0.07)$ recall condition, $\mathrm{F}(1,114)=10.53, \mathrm{p}<.001$. However, it was only under delayed recall that subjects made more intrusions associated with the American $(M=0.50)$ than the Soviet $(M=0.11)$ defectors, $\mathrm{F}(1,114)=7.24, \mathrm{p}<.008$ (means were 0.07 in the immediate recall condition for both the Soviet and the American defectors) .

The foregoing analyses showed that more country-oriented intrusions accompanied the article about Soviet defectors and more personality-oriented intrusions accompanied the article about American defectors.' The analyses suggested that both a countryoriented and a personality-oriented CKS component were available to subjects and that these components were differentially used as a function of nationality of defectors.

Unsolicited attributions. Two coders rated subjects' un-solicited attributions on a scale from 1 (something about the country caused the defection) through 3 (something about both the country and the defectors' personality caused the defection) to 5 ( something about the defectors' personality caused the defection). Intercoder agreement was high, $r=.87, p<.0001$. The mean coder score for each subject was used in the analyses.

We expected that subjects' CKSs would lead them to interpret the defection of the Soviet citizens as due to imperfections of the Soviet political/economic system and the defection of the American citizens as due to personality characteristics of the defectors. This pattern was confirmed. An ANOVA revealed a main effect of defectors, indicating that subjects tended to make relatively more country (and fewer personality) attributions for the Soviet defection $(M=2.36)$ than for the American defection $(M=3.28), \mathrm{F}(1,116)=27.84, \mathrm{p}<.00001$. The absence of a significant main effect of time period, $\mathrm{F}(1,116)=2.66, \mathrm{p}<.11$, and the absence of a significant interaction, $\mathrm{F}(1,116)=0.75, \mathrm{p}<.39$, revealed that the CKS-based pattern of attributions was not influenced by delay of recall.

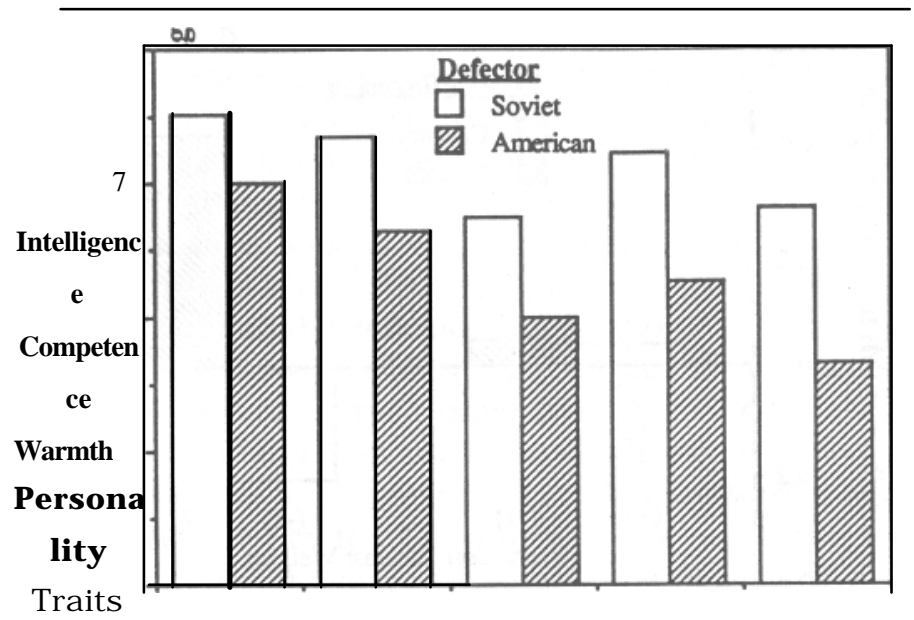

Figure S Mean personality trait ratings for Soviet and American defectors, Experiment 2.

Open-ended attributions. The same coding scheme was used for open-ended attributions as for unsolicited attributions. Intercoder reliability was high, $r=.84, \mathrm{p}<.0001$. The mean coder score for each subject was used in all analyses.

We expected that subjects' CKSs would lead them to make relatively more country-related attributions for the Soviet defectors and relatively more personality-related attributions for the American defectors. The defectors main effect revealed exactly this pattern $(\mathrm{Ms}=1.63$ and 2.97 for Soviet and American defectors, respectively), F(1, $116)=43.71, \mathrm{p}<.00001$. This CKS-based attributional pattern was constant across the two recall conditions, as indicated by the nonsignificant time period main effect and interaction, Fs $<1$.

Personality ratings. It was expected that the defector CKS would manifest itself in more negative perceptions of the personalities of the Perrins than of the personalities of the Andronovs. The American defectors, compared with their Soviet counterparts, were indeed rated as less intelligent, less competent, less warm, and less moral. Furthermore, subjects were more sympathetic to the case of the Soviet than the American defectors. Only the defectors main effects were significant, all $\mathrm{Fs}(1,116)>$ 15.49, ps $<.00001$. Means are provided in Figure 3.

Correlations between memory and attributions. It is evident from the results reported above that delay of recall affected memory but not attributions. Memory intrusions (i.e., country-oriented intrusions for the Soviet defectors and personality-oriented intrusions for the American defectors) occurred almost exclusively in the delayed recall 


\section{PERSONALITYAND SOCIAL PSYCHOLOGY BULLETIN}

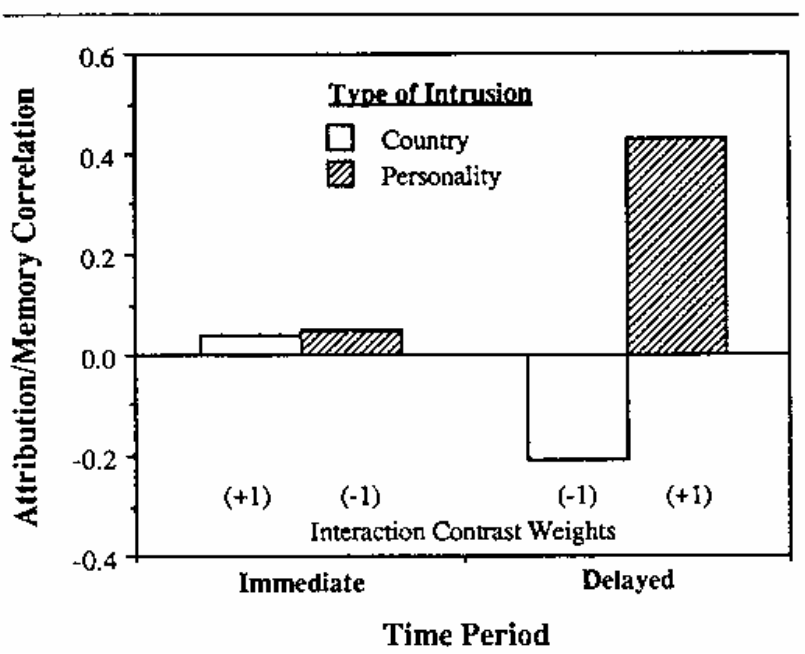

Figure 4. Correlations between attributions and memory intrusions as a function of time period and type of intrusion Experment 2.

condition. However, attributional patterns did not differ between the delayed and immediate recall conditions.

It is likely that attributions were made spontaneously and on-line as subjects were going through the stimulus essay (see Hastie, 1984; Pryor, 1986; Uleman, 1987; Weiner, 1985) and were stored in memory separately from the details of the essay. Furthermore, the delayed CKS effect on memory intrusions may take place through recall of the original spontaneous on-line attribution. In essence, delay subjects may have recalled the spontaneous attribution they made during the initial reading of the materials and then used that CKS-based attribution as a memory cue for specific details. If so, then we should expect attributions to correlate with intrusions in the delay conditions but not in the immediate conditions.

To test this hypothesis, we first averaged the two attribution measures (unsolicited and open-ended). Once again, a low attribution score indicates an attribution to country qualities (situational), whereas a high attribution score indicates an attribution to personality qualities (dispositional). These attribution scores were then correlated with number of country-oriented instrusions for the Soviet defectors and with the number of personalityoriented intrusions for the American defectors. The results are presented in Figure 4.

The pattern of correlations is exactly as predicted. In the immediate recall conditions, there was no relation between subjects' attributions for the defection and memory intrusions. However, in the delayed recall conditions, subjects who tended to attribute the defection to country qualities (low attribution score) made more countryoriented intrusions $(\mathrm{r}=-.21)$, whereas those who tended to attribute the defection to personality qualities (high

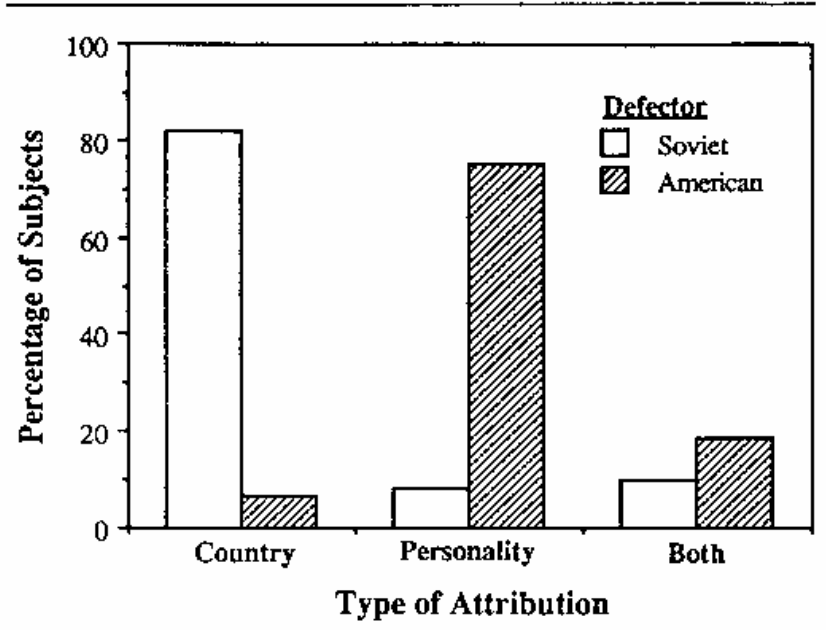

Figure 5 Percentage of subjects generating country-oriented, personal oriented, or both types of attributions, Experiment 2.

attribution score) made more personality-oriented trusions $(r=.43)$.

To test the significance of this pattern, we adopted $t$ somewhat conservative procedure for testing an int action pattern of correlations described by Andersi Jennings, and Arnoult (1988, pp. 983-984). Specifica we converted the correlations to $z$ scores and construc the $2 \times 2$ interaction contrast. This procedure is cons vative in that the error term is inflated because $t$ correlations are not all independent. Nonetheless, $t$ predicted contrast (see contrast weights in Figure 4) v significant, $z=2.51, p<.02$. Thus, although this exp ment was not designed to test the notion that delay memory intrusions result from attributional cues, $t$ data are entirely consistent with this notion.

Replication of E x periment 1. The replication was intendec ascertain that subjects in Experiment 2 held the sa CKSs as subjects in Experiment 1. A coding scher identical to that used in Experiment 1 was adopt Coders agreed on 83\% of the cases and resolved c agreements through discussion. Eighty-two percent the subjects who were asked why Soviets defect to $t$ United States stated that something about the count causes defection. Seventy-five percent of the subjec who attempted to explain why Americans defect to t Soviet Union stated that something about the defecto personality causes defection (Figure 5). A log-linear c square analysis revealed a significant defectors $m$ i effect, $\mathrm{X}^{2}(2)=45.25, \mathrm{p}<.0001$. Neither the time peri main effect nor the interaction was significant, $\mathrm{X}^{2}(2$ $0.27, \mathrm{p}<.87$, and $\mathrm{X}^{2}(2)=0.01, \mathrm{p}<.99$, respectively. The results are consistent with the assertion that subjects Experiment 2 held the same CKSs as subjects in Expr ment 1 . 


\section{GENERAL. DISCUSSION}

\section{Summary of Findings}

The major objective of this research was to provide a clean test of the CKS approach to understanding social perception by adopting Fiedler's criteria for validating CKSs. Experiment 1 supplied evidence for the existence of a defection CKS. CKS-consistent intrusions in subjects' free recall protocols in Experiment 2 furnished independent evidence of the effects of CKSs on the processing of social information.

In addition, varied stimulus information instigated the use of different CKSs, as manifested in subjects' attributions. And through a converging operations approach, several functional CKS properties (i.e., intrusions in free recall, pattern of attributions, evaluative tone of personality ratings) were demonstrated. All this occurred with the use of event rather than trait stimulus information, as suggested by Fiedler. Event information was relatively ambiguous and complex and allowed subjects to use their CKSs at the encoding stage.

A final finding of interest was the memory/attribution relation. There was virtually no relation in immediate recall conditions, but moderate correlations emerged in delayed conditions.

\section{Basis of Defection CKSs}

What is the basis for subjects' holding the CKSs that we found? The CKSs may be due to a tendency to make situational attributions when someone moves from a less desirable to a more desirable place (e.g., from the Soviet Union to the United States) but dispositional attributions when someone surprisingly moves from a more desirable to a less desirable place. The evaluative tone of personality ratings (i.e., strongly negative ratings for the American defectors and strongly positive ratings for the Soviet defectors) is certainly consistent with the view. People who make such obviously bad decisions (i.e., the American defectors, given the CKS in use) are likely to be seen as less good or more bad on many dimensions (see Schneider, 1973). Alternatively, perceiving the American defectors negatively may have been used as a strategy by subjects in order to distance themselves from the defectors, probably because the defectors harmed their collective self-esteem (see Marques \& Yzerbyt, 1988; Marques, Yzerbyt, \& Leyens, 1988).

\section{The Memory/Attributions Relation}

An interesting finding involved the weak association between memory and attribution/personality ratings. Although memory intrusions increased over time, attri butions and personality ratings did not become more extreme. Furthermore, the memory/attribution relation increased with time. This asymmetry can be ex- plained by considering a reconstructive recall hypothe sis. According to this hypothesis, memories for the defection episode in the delayed condition were guided by the subjects' CKSs. Meanwhile, attributions in the delayed condition were retrieved versions that had been spontaneously generated (Hastie \& Park, 1986; Weiner, 1985; Winter \& Uleman, 1984) when subjects were first presented with the defection information.

An alternative possibility is that subjects in the delaye conditions recalled their spontaneously generated attri butions first and then used those attributions as recall cues. Because the spontaneous attributions were them selves affected by the CKSs, they would cue memories (both correct and intrusions) that were largely congruen with the CKSs.

Although the present data do not distinguish betweer these two related possibilities, they do clearly rule out a third. It is commonly assumed that judgments are baser on recalled facts related to the judgment. Had this been the case among our subjects, we should have observec attribution and personality rating shifts across time par allel to the memory shifts. Because such shifts did not occur for either personality or attribution measures, we can assume that these judgments were not based on re called facts. In addition, the shift in memory/attributior correlations contradicts this third possibility.

\section{Implications for Political Ideology}

The present research has implications for conceptu alizations of political ideology. The veridicality and na ture of political ideology have been the focus of a long standing debate among political scientists (see Kinder Sears, 1985, for a critical review). Political ideology ha: been conceptualized as a "core belief system" (Lane, 1973) "ideological principles" (Marcus, Tabb, \& Sullivan, 1974) "general ideological dimensions" (Jackson \& Marcus 1975), and "general political orientations" (Thomas 1978) . Other views of political ideology include people's causal accounts of poverty (Feather, 1974; Furnham, 1982a) and unemployment (Furnham, 1982b; Williams 1984; see also Axelrod, 1976; Conover \& Feldman, 1984 George, 1979; Hoagland \& Walker, 1979). The present perspective is certainly compatible with the above-noter ones. However, the present perspective goes beyond the previous ones in its emphasis on uncovering the struc tural characteristics and processing consequences 0 . CKSs. Thinking of political ideology as a set of CKSs car effectively answer questions about the way citizens pro cess new political information and the way they store anc use this information to make attributions, form impres sions, or draw inferences. Consequently, viewing politica ideology as CKSs can advance our understanding of the specific cognitive processes through which citizens cog nize their political world. 


\section{PERSONALITYAND SOCIAL PSYCHOLOGY BULLETIN}

\author{
Appendix A \\ "Newspaper Article" on Soviet \\ Defectors, Created for Experiment 2 \\ THE NEW YORK TIMES \\ Soviet Cancer Researcher and Family Defect to the United States
}

Associated Press

WASHINGTON-on Wednesday, Ivan Andronov, a Soviet cancer researcher defected to the United States.

Andronov, his wife and three children arrived in Washington Wednesday after being granted political asylum.

Andronov is a 45-year-old biochemist and oncologist who headed the cancer research laboratory at Prietsky Hospital in Leningrad from 1980 until September, 1986.

A man, woman and three children, identified as Andronov, his wife, Iona, and their children, were shown on the U.S. evening news.

Speaking in Russian, Andronov told viewers that he and his wife had opposed the war in Afghanistan and fought for social freedoms in the Soviet Union ever since.

Andronov said that he and his wife made a "very difficult" decision to leave the Soviet Union.

\section{Appendix B \\ "Newspaper Article" on American \\ Defectors, Created for Experiment 2 \\ THE NEW YORK TIMES \\ American Cancer Researcher and Family Defect to the Soviet Union}

A- ssociated Press

MOSCOW-On Wednesday, James Perrin, an American cancer researcher defected to the Soviet Union.

Perrin, his wife and three children arrived in Moscow Wednesday afte $r$ being granted political asylum.

Perrin is a 45-year-old biochemist and oncologist who headed the cancer research laboratory at St. Joseph's Hospital in Houston from 1980 until September, 1986.

A man, woman and three children, identified as Perrin, his wife, Deborah, and their children, were shown on the Soviet evening news.
Speaking in English, Perrin told viewers that he and his wife had opposed the Vietnam war and fought for social freedoms in the United States ever since.

Perrin said that he and his wife made a "very difficult" decision to leave the United States.

NOTES

1. Fiedler (1982) presented his position as a critique of the Kelleyar notion of a causal schema. Kelley (1972) defined causal schemata as abstract causal patterns of thought that are used either individually or collectively in accounting for causality in the social domain. Fiedler's critique was actually directed toward content-dependent CKSs, much like the defection CKSs tested in the present research.

2 . Identical results were obtained by a nalyzing proportion of intrusions rather than number of intrusions.

REFERENCES

Abelson, R. P. (1968). Psychological implication. In R. P. Abelson E. Aronson, W. J. McGuire, T. M. Newcomb, M. J. Rosenberg, \& P. H. Tannenbaum (Eds.) , Theories of cognitive consistency: A sourceboo) (pp. 112-139). Skokie, IL: Rand McNally.

Abelson, R. P. (1973). The structure of belief systems. In C. Schank \& K. M. Colby (Eds.), Computer models of thought and language(pp. 287-339). New York: W. H. Freeman.

Anderson, C. A. (1983). The causal structure of situations: The generation of plausible causal attributions as a function of type of event situation. Joumal of Experimental Social Psychology, 19, 185-203.

Anderson, C. A. (1985). Actor and observer attributions for different types of situations: Causal structure effects, individual differences, and the dimensionality of causes. Social Cognition, 3, 323-340.

Anderson, C. A., Jennings, D. L., \& Arnoult, L. H. (1988). Validity and utility of the attributional style construct at a moderate level of specificity. Joumal ofPersona\&ty and Social Psychology, 55,979-990.

Anderson, C. A., New, B. L., \& Spear,J. R (1985). Argument availability as a mediator of social theory perseverance. Social Cognition, 3, 235-249.

Anderson, C. A., \& Slusher, M. P. (1986). Relocating motivational effects: A synthesis of cognitive and motivational effects on attributions for success and failure. Social Cognition, 4, 270-292.

Anderson, C. A., \& Weiner, B. (in press). Attribution and attributional processes in personality. In G. Caprara \& G. Heck (Eds.), Modern personality psychology: Critical reviews and newdirections. Hempstead, England: Harvester-Wheatsheaf. 
Axelrod, R. (1976). Structure of decision. Princeton, NJ: Princeton University Press.

Black, J. B., Galambos, J. A., \& Read, S. J. (1984). Comprehending stories and social situations. In R. S. Wyer, Jr., \& T. K. Scull (Eds.), Handbook of social cognition (Vol. 3, pp. 45-86). Hillsdale, NJ: Lawrence Erlbaum.

Bower, G. H. (1976). Experiments on story understanding and recall. Quarterty Joumalof Experimental Psychology, 28, 51 1-534.

Bower, G. H., Black, J. B., \& Turner, J. T. (1979). Scripts in text comprehension and memory. Cognitive Psychology, 11, 177-220.

Bransford, J. D., \& Franks, J. J. (1971). The abstraction of linguistic ideas. CognitivePsychology, 2,331-350.

Conover, P.J., \& Feldman, S. (1984). How people organize the political world. American Joumal of Political Sciences, 25, 617-645.

Feather, N. T. (1974). Explanations of poverty in Australian and American samples: The person, society, or fate? Australian Joumal of Psychology, 26, 199-2 16.

Fiedler, K. (1982). Causal schemata: Review and criticism of research on a popular construct. Joumal of Personality and Social Psychology, 42, 1001-1013.

Furnham, A. (1982a). Why are the poor always with us? Explanations for poverty in Britain. British Joumalof Social Psychology, 21,311-322.

Furnham, A. (1982b). Explanations for unemployment in Britain. European Journal of Social Psychology, 12, 335-352.

George, A. L. (1979). The causal nexus between cognitive beliefs and decision-making behavior: The "operational code" belief system. In L.S. Falkowski (Ed.), Psychological models in international politics (pp. 95-125). Boulder, CO: Westview Press.

Gilbert, D. T., Pelham, B. W., \& Krull, D. S. (1988). On cognitive busyness: When person perceivers meet persons perceived. Journal of Personality and Social Psychology, 54, 733740

Hamilton, D. L. (1988). Causal attribution viewed from an information-processing perspective. In D. Bar-Tal \& A. Kruglanski (Eds.), The social psychology of knowledge (pp. 359385). Cambridge: Cambridge University Press.

Harvey, J. H., Yarkin, K. L., Lightner, J. M., \& Town, J. P. (1980). Un-solicited interpretation and recall of interpersonal events. Journal of Personality and Social Psychology, 38, 551-568.

Hastie, R. (1984). Causes and effects of causal attribution. Journal of Personality and Social Psychology, 46, 44-56.

Hastie, R., \& Park, B. (1986). The relationship between memory and judgment depends on whether the judgment task is memory-based or on-line. Psychological Review, 93, 258-268.
Higgins, E. T., Rholes, W. S., \&Jones, C. R. (1977). Category accessibility and impression formation. Journal of Experimental Social Psychology, 13, 141-154.

Hilton, D. J. (1988). Contemporary science and natural explanation: Corn monsense conceptions of causality. Brighton, England: Harvester.

Hoagland, S. W., \& Walker, S. G. (1979). Operational codes and crisis outcomes. In L. S. Falkowski (Ed.), Psychological models in international politics (pp. 125167). Boulder, CO: Westview Press.

Hoffman, C., Mischel, W., \& Mazze, K. (1981). The role of purpose in the organization of information about behavior: Trait-based versus goal-based categories in person cognition. Journal of Personality and Social Psychology, 40, 211-225.

Jackson, T. H., \& Marcus, G. E. (1975). Political competence and ideological constraint. Social Science Research, 4, 93-111.

Kahneman, D., Slovic, P., \& Tversky, A. (Eds.). (1982). Judgment under uncertainty: Heuristics and biases. London: Cambridge University Press.

Kelley, H. H. (1972). Causal schemata and the attribution process. In E. Jones, D. E. Kanouse, H. H. Kelley, R. S.

Nisbett, S. Valins, \& B. Weiner (Eds.), Attribution: Perceiving the causes of behavior ( $p p .151-174)$. Morristown, NJ: General Learning Press.

Kelley, H. H. (1983). Epilogue: Perceived causal structures. InJ.Jaspars, Fincham, \& M. Hewstone (Eds.), Attribution theory and research: Conceptual developmental and social dimensions (pp. 388-415). London: Academic Press.

Kim, M. P., \& Rosenberg, S. (1980). Comparison of two structural models of implicit personality theory. Journal of Personality and Social Psychology, 38, 375-389.

Kinder, D. R., \& Sears, D. O. (1985). Public opinion and political action. In G. Lindzey \& $\mathrm{E}$. Aronson (Eds.), The handbook of social psychology (pp. 659-741). New York: Random House.

Kruglanski, A. W. (1989). Lay epistemics and human knowledge.. Cognitive and motivational biases. New York: Plenum.

Kunda, Z. (1987). Motivation and inference: Self-serving generation and evaluation of evidence. Journal of Personality and SocialPsychology, 53, 636-647.

Kunda, Z. (1990). The case for motivated reasoning. Psychological Bulletin, 108, 480.498.

Lalljee, M., \& Abelson, R. P. (1983). The organization of explanations. In M. Hewstone (Ed.), Attribution theory: Social and functional extensions (pp. 65-80). Oxford: Blackwell.

Lane, R. E. (1973). Patterns of political belief. In J. Knutson (Ed.), 


\section{PERSONALITYAND SOCIAL PSYCHOLOGY BULLETIN}

Handbook of political psychology. San Francisco: JosseyBass.

Marcus, G., Tabb, D., \& Sullivan, J. L. (1974). The application of individual differences scaling to the measurement of political ideologies. American Journal of Political Science, 18, 405-420.

Markus, H., Crane, M., Bernstein, S., \& Siladi, M. (1982). Self-schemas and gender. Journal of Personality and Social Psychology, 42, 38-50.

Marques, J. M., \& Yzerbyt, V. Y. (1988). The black sheep effect: Judgmental extremity towards ingroup members in inter- and intra-group situations. European Journal of Social Psychology, 18, 287-292.

Marques, J. M., Yzerbyt, V. Y., \& Leyens, J.-P. (1988). The black sheep effect Judgmental extremity towards ingroup members as a function of group identification. European Journal of SocialPsychology, 18,1-16.

Nisbett, K. E., \& Ross, L. (1980). Human inferences: Strategies and short-comings. Englewood Cliffs, NJ: Prentice-Hall.

Osgood, C. E., Suci, G., \& Tannenbaum, P. M. (1957). The measurement of meaning. Urbana: University of Illinois Press.

Peterson, C. (1980). Memory and the "dispositional shift." Social Psychology Quarterly, 43, 372-380.

Pryor, J. B. (1986). The influence of different encoding sets upon the formation of illusory correlations and group impressions. Personality and Social Psychology Bulletin, 12, 216-226.

Read, S. J. (1987). Constructing causal scenarios: A knowledge structure approach to causal reasoning. Journal of Personality and Social Psychology, 52, 288-302.

Rosenberg, S. (1976). New approaches to the analysis of personal con-structs in person perception. In A. W. Lanfield (Ed.), Nebraska Symposium on Motivation ( $p p .179$ 242). Lincoln: University of Nebraska Press.

Rosenberg, S., \& Sedlak, A. (1972). Structural representations of implicit personality theory. In $\mathrm{L}$. Berkowitz (Ed.), Advances in experimentalsocial psychology (Vol. 6, pp. 235-297) . Orlando, FL: Academic Press.

Schank, it C., \& Abelson, R. P. (1977). Scripts, plans, goals and under-standing. Hillsdale, NJ: Lawrence Erlbaum.

Schneider, D. J. (1973). Implicit personality theory: A review. Psychological Bulletin, 79, 294-319.

Thomas, D. (1978). Political belief systems and ideoaffective resonance: The structuring principle revisited. Experimental Journal of Politics, 6, 34-89.

Uleman, J. S. (1987). Consciousness and control: The case of spontaneous trait inferences. Personality and Social Psychology Bulletin, 13, 337-354.
Weiner, B. (1985). "Spontaneous" causal thinking. Psychological Bulletin, 97, 74-84.

Wells, G. L. (1982). Attribution and reconstructive memory. Joumal of Experimental Social Psychology, 18, 447-463.

Williams, S. (1984). Left-right ideological differences in blaming victims. Political Psychology, 5, 573-581.

Winter, L., \& Uleman, J. S. (1984). When are social judgments made? Evidence for the spontaneousness of trait inferences. Joumal of Personality and Social Psychology, 45, 237-252.

Wyer, R. S., Srull, T. K., Gordon, S. E., \& Hartwick, J. (1982). Effects of processing objectives on the recall of prose material. Joumal of Personali ty and Social Psychology, 43, 674-688.

Received March 19, 1991

Revision received June 19,

1991 Accepted June 20,

1991 